lei, usant de crédit et de même la profession d'expert-comptable devant les autorités judiciaires, administratives et financières etc., ne poura êtr'e exel'céc que par les personnes faisant partie de ce corps.

Il fait satisfaire aux conditions suivantes pour pouvoir être inscrit dans ce Corps.

Etre ancien élève d'une Académie des Hautes-Etudes commerciales de Roumanic ou de l'Etr'anger, ou encore êtr'e ancien élève d'une Ecole Supérieure de commerce, ou d'une école de commeree (cours supérieurs du soir).

Htice cll possession de ses droits civils.

$\mathrm{N}$ 'avoir subi aucune condamnation de nature infamante.

Auprès de chaque tribunal fonctionne une section ayant de caractère d'une per'sonne morale.

Auprès de la Cour d'Appel de Bucarest fonctionnera le "Conseil Supérieur du Corps", en plus de la section d'Ilfov.

Au mois de janvier de chaque année le Conseil de chaque section fera un tableau des membres de la section.

Le tableau comprendra trois catégories de membres:

Les comptables stagiaires, c.à.d. ceux qui, en possession des tit res indiqués ci-dessus, s'exerecnt à la comptabilité depuis dcux ans, à dater de leur inscription dans le Corps, auprès d'une cntreprise dont les opérations sont enregistrées selon les règles de la comptabilité.

Los comptables autorisés, c. à. d. ceux qui, prouveront au Conseil de la section intéressée, l'accomplissement des deux années de practique.

les experts-comptables, c. à. d. ceux qui, après avoir prouvé qu'ils pratiquent la profession depuis 5 ans, à dater de leur inscription dans le Corps, se verront reconnaître cette qualité par le Conseil supérieur du Corps, après avis dûment motivé de la section respective.

Les professeurs de comptabilité ayant subi l'examen de capaeité, sont de droit experts-comptables.

Les persommes possédant des titres académiques peuvent étre promues au grade d'expert-comptable après deux ans d'exercice du métier, mais seulement si elles ont fonetionné comme comptables auprès d'une entreprise dont les opérations sont enregistrées selon les régles de la comptabilité.

Pour la surveillance et la défense des intérêts des sociétés de bicnfaisance, de ceux qui sont sous tutelle, sous curatelle, pour les communautés de biens ete. les tribunaux délégueront un expert-comptable, ou un comptable autorisé, au moins une fois par an, en vue de verifier la gestion et de faire un rapport. Le comptable délégué sera obligé, dans le délai d'un mois, à dater de sa délégation, de faire ce rapport sous peine d'une amende de 500 à 1.000 hei.

Au moins I'un des censeurs des sociétés anonymes, ayant un capital versé d'au moins 5.000 .000 - lei, sociétés créées aplès la promulgation de la présente loi, devra être comptable autorisé ou cxpert-comptable, remplissant les conditions prévues au Code de Commerce.

Les entreprises prévues à l'art. précédent ne pourront obtenir du Tribunal le visa des livres à la fin de l'année, que si les livres sont signés par un comptable autorisé ou expert-comptable.

Pour toute expertise de comptabilité dans les cas de moratoires et de faillite, de procès dans lesquels il s'agit de comptes, d'impositions fiscales, d'arbitr'ages en matière d'inventaires et de bilans, de partages, de l'établissement de revenus et de dépenses, les autorités financières, administratives et judiciaires se serviront d'un expert-comptable pris sur le tableau, en tenant toutefois compte, autant que faire se pourra de la spécialité et de la rotation.

Les comptables autorisés, ainsi que les experts-comptables, devront examiner attentivement les bilans, ou tout autre ques- tion dont ils sont chargés, et cela aussi bien dans l'intérêt public, que dans l'intérêt de la partic qui les en a chargés.

Ils sont tenus de signer les livres et les actes qui leur sont confiés et de répondre de la régularité des travaux.

Ils sont également tenus de garder le plus strict secret sur les faits dont ils ont eu connaissance à l'occasion de l'exercice de leurs fonctions.

Il est vrai que la profession de ,,accountant" comme elle est pratiquée en Angleterre ou en Hollande n'est pas cncore développée en Rounanie. Les experts comptables sont tous, à-peuprès, des directeurs ou bien des fonctionnaires supérieur's daus diverses entreprises et ne font qu'aceidentellement des expertises. 1ls ne sont appelés à verifier ou diriger la comptabilité des administrations comme il est habitude dans les pays du Nord.

L'activité d'expert se manifeste à l'occasion des vérifications demandées par le fise, par les autorités judiciailes en cas de moratoire, de faillite ou bien dans des yuestions pénales. Les expertises penales sont mal payées et on touche difficilement les montants ordonnés conme honoraires.

Fin tout cas, on peut dire, que la profession de comptable et d expert comptable a été réglementée en Roumanie sur la base d études spéciales dans les écoles de commerce et de pratique professionnclle.

PETRU DRAGANESCO BRATESH

\section{UIT HET BUITENLAND}

\section{Red.: J. E. ERDMAN, JAC. H. KRAMER en C. J. MEYER (Bijdragen en mededeelingen zende men aan den Secretaris der Redactie)}

\section{Een Centrale Kas in groote Warenhuizen}

In „Mon Bureau”, van April 1927 komt een bechrijving roor inzake de werking van de centrale kas in „Les Grands Magasins du P'rintemps" te Parijs.

Volgens den schrijver van het artikel bestaan er verschillende voordeclen voor dit systeem. De vijf voornaamste zijn:

$1^{\circ}$. het voorkomt het lange en onaangename wachten van de clientèle aan de kassen,

$2^{\circ}$. het voorkomt voor het personeel het tijdverlies tengevolge van het hecn en weer loopen van de rayons naar de afdeelingskassen; de verkooper's blijven in hun rayon en kumnen zich dientengevolge geheel aan den verkoop wijden; hun rendement verhoogt zich,

$3^{\circ}$. de magazijnen zelve zijn bevrijd van het heen en weer loopen van de rayons naar de kassen en van de kassen zelve alsmede van de rij van clienten, die hun beurt afwachten.

$4^{\circ}$. de centrale kas neemt juist die ruimte in beslag, die voor den verkoop weinig geschikt is, terwijl anderzijds de rust in de centrale kas in tegenstelling met het rumoer bij de afdeelingskassen, bevorderlijk werkt op de arbeidsprestatie vall de caissières,

$5^{\circ}$. er is een betere schakel tusschen de diverse afdeelingen en de boekhouding.

Resumeerende zegt de schrijver, dat de centralisatie der kassen tot gevolg heeft een beter gebruik van het personeel, van de ruimte en van den tijd.

Het systeem komt in het kort hicrop neer: Iedere verkooptafel in het warenhuis heeft een nummer en is door middel van een luchtbuisleiding met de centrale kas verbonden.

Is een verkoop tot stand gekomen, dan ontvangt de verkoopster het geld van den elient, doet dat tezamen met de door haar uitgeschreven bon in een metalen kasdoes, die door middel 
van luchtdruk naar de centrale kas gaat. De kardoes heeft hetzelfde nummer als de tafel van de verkoopster.

Gaat de verkoop op rekening, dan doet de verkoopster de bon in een fibre-kardoes.

In de centrale kas worden de kardoezen der contante verkoopen en die der verkoopen op rekening electrisch gesortecrd (reden waarom de samenstclling van de kardoezen de eene keer van metaal en de andere keer van fibre is). De kardoezen met geld-inhoud komen op banden (tapis roulant) te liggen, die ze naar de kashoudsters vocren ter behandeling. De kashoudsters zijn zoo geplaatst, dat zij de kardoezen op de banden zien aankomen.

De kaldoezcn, die bestelling op rekening betreffen, loopen over cen andere band naar de afdeeling ,Rekening-Courant".

Zijn de kardoezen in de afdeeling „Contant" of „Rekg. Crt." behandeld, dan worden zij weer op den transportband gelegd die ze nalar het einde van de tafel brengt. Aldaar aangekomen worden de Kardoezen gesorteerd op nummer en onmiddellijk in de desbetreffende buisleiding gedaan om alsdan een oogenblik later weder bij het nitgangspunt, d.i. de tafel van de be. treffende rerkoopster te belantien.

\section{Herziening van den Kalender}

In "The Journal of Accountancy", van Maart komt een artikel voor, waldin een herzicning van de tijdverdeeling wordt bepleit. Het jaar zou dan volgens het zoogenaamde, fixed calendar plan" verdeeld zijn in 13 maanden van 4 weken ieder. Paschen zou steeds op dezelfde dagen kumnen vallen en Nicuwjaarsdag (zijnde te kort aan de $13 \times 4 \times 7=364 \mathrm{dg}$.) zou worden aangeduid met 0 Januari en de extra dag van het schrikkeljaar met 0 Juli. Dezc beide dagen zouden intemationale feestdagen moeten worden, waardoor dan (niet in aanmerking genomen de nationale feestdagen) bereikt wordt cen over de gehecle christelijke wereld gelijke verdeeling van den tijd in werk- en rustdagen. Voor de groote bedrijven zouden dan de statisticken van verbruik, productie, kosten ete. loopen over weken van h.v. $51 / 2$ werkdag en over maanden van $4 X$ $51 / 2$ werkdag. De maanden zijn dan zonder correctie, onmiddellijk vergelijkbaar (voor feestdagen blijft die correctie noodig) en eveneens zijn de weken on maanden van vorige jaren direct met de zoo juist afgeloopen wioken en maanden vergelijkbatr.

Het zoogenaamde "Zwitsersche plan" beoogt slechts de uniformiteit van perioden van 3 maanden. Deze maanden bestaan dan uit 30,30 en 31 dagen. De eerste dikg van ieder kwartaal zou zijn een Maandag en de laatste dag een Zondag. Nieuwjaalssdag is een extra dag evenals de 366 ste dag van een schrikkeljaar.

Je 3de maand heeft 5 Zondagen en dus $31-5=26$ werkdagen evenals de $1 \mathrm{e}$ en $2 \mathrm{e}$ maand. De 5 Zaterdagen, die in de $3 e$ maand voorkomen maken de vergelijking met de $1 \mathrm{c}$ en 2e maand, waarin 4 Zaterdagen voorkomen, zonder correctie niet mogelijk. Iedere maand van dat systeem is natuurlijk direct vergelijkbaar met de overeenkomstige maand in een vorig jaar, ondat ook in lict Zwitsersche plan de Paschen op een be parden dag is rastgesteld.

Volgens den schrijver ran het artikel, zijn bij de thans bestaande tijdsverdeeling slechts $35-57 \%$ van de maanden der jaren $1901 \mathrm{t} / \mathrm{m} 1928$ direct vergelijkbaar. Hij berekent, dat "hy ,avoiding the time and money wasted in searching for and ,referring to ealcndar's and in drafting, advertising printing ,and law costs of such phrases as ,Tuestay after the first "Monday" ete." een bedrag van \$ 30.000.000 - in de Vereenigde Staten van Amerika zou bespaard worden.

\section{Inventariswaarde van Films}

Volgens den schrijver van het desbetreffende artikel in ,'The Jomrnal of Accountancy" van Maart is ,the product of the ,motion-picture ,factory" nothing more than a strip of "developed negative film several thousand feet in length from ,which positive copies (prints) may be made for use in the .plojection machines of the exhibitors. Condensed into this "strip are enormous sums expended for salaries and wages, .for lumber, hardware, properties, costumes ete. and for the "fixed charges of the studio."

,For purposes other than the making of positives to be ,exhibited in the theatres, the negative is worth tangibly only "the serap value of the relluloid. But for the purpose of exhibi,ting the positives, its worth is actually measured by the ineome „it will produce."

De verschillende fabrikanten hebben tafels aangelegd waaruit blijkt de gemiddelde ,levensduur" van een film en wat elke 4 weken (le opbrengst van de verhuurde films (positieven) is geweest. Hieruit wordt voor iedere periode van 4 weken cen afschrijvings-percentage voor de negatieven en de positieven vastgesteld.

Uit de gegeven cijfer's blijkt na een periode van $4 \times 4$ weken de residu-waarde van het negatief tot $\pm 50 \%$ van den kostprijs is gedarald.

Bij de positieven worden reparatiekosten bij den kostprijs geteld, doch de afschrijving hecft in een sneller tempo plaats dan bij de desbetreffende negatieven.

J. E. E.

\section{VRAGENBUS}

Vragen omtrent onderwerpen, die voor den accountant in de uitoefening van zijn beroep van belang kunnen zijn, kunnen worden ingezonden bij den Secretaris van de Redactie.

De Rodactie is bereid, om de grenzen, waarbinnen de vragen, die voor beantwoording in aanmerking komen, zoo ruim mogelijk te stellen, zoodat zoowel die van juridischen, als die van bedrïfshuishoudkundigen aard daar binnen vallen, mits de vragen slechls blijven binnen het gebied, dat het blad dienen wil.

De beantwoording geschicdt door één der medewerkers of redactieleden individueel, zoodat de antwoorden niet mogen worden geacht steeds de meening der Redactie in haar geheel weer te geven.

\section{VRAAG No. 13}

Hoe moet de accountant zich gedragen als verdediger van bijzondere geldelijke belangen?

Welke houding behoort de accountant aan te nemen in gevallen als het volgende:

$X$. wil zijn zaak overdoen aan Y. Beiden laten zich bij de onderhandelingen bijstaan door hun accountants. Moeten dezen objectief oordeelen op pleiten in het belang van hun opdrachtgever? Hoe moeten zij handelen wamneer hun opdrachtgever overviaagt, heele of halve onwaarheden verkondigt, veel te optimistische voorstellingen omtrent de toekomst doet enz. Kunnen zij in die gevallen passief blijven of moeten zij ingrijpen, omdat hun anwezigheid en stilzwijgen anders een vertrouwen zou kunnen opwekken, dat niet gerechtvaardigd is?

\section{ANTWOORD :}

Men zie het hoofdartikel in dit nummer. 